\title{
Correlates of Antenatal and Postnatal Care among Tribal Women in India
}

\author{
A. Sathiya Susuman \\ Department of Statistics, University of the Western Cape, Private Bag X17, \\ Bellville 7535, Cape Town, South Africa \\ E-mail: sappunni@uwc.ac.za
}

KEYWORDS Health Care. Antenatal. Postnatal. Pregnancy. Chhatisgarh

\begin{abstract}
It is well established that those women who undergo full antenatal care check-up and give birth in a medical institution or whose delivery is attended by trained paramedical persons promotes child survival and reduces maternal mortality. In the light of the above, an attempt is made in this paper to relate the socio-economic and demographic characteristics of the currently married Schedule Tribes' women in eight districts of Chhatisgarh with factors associated with antenatal and postnatal care. Data for this study were taken from District Level Household Survey on Reproductive and Child Health (DLHSRCH 2002), a representative sample of 1569 Scheduled Tribes' currently married women aged 15-44, residing in eight districts of Chhatisgarh. Adjusted effects (odds ratios) analysis has been used to find out the effects of antenatal and post-natal care on institutional delivery in Chhatisgarh. It is observed that majority of the Scheduled Tribes' women, about 84 percent, have a low standard of living. Also, 74 per cent of the Scheduled Tribes' women are illiterate. The finding of the adjusted effects (odds ratio) shows that giving birth in the medical institution for the Scheduled Tribes' women who received full antenatal check up is 2.5 times higher than those women who did not receive any antenatal check-up. It suggests that majority of the currently married Scheduled Tribe women have low standard of living there is a need to improve their economic standard so that they can fulfill their basic needs.
\end{abstract}

\section{INTRODUCTION}

Antenatal care is an essential safety net for healthy motherhood and childbirth, where the well-being of both the prospective mother and her offspring can be monitored (United Nations 2008). The proportion of pregnant women in the developing countries who had at least one antenatal care visit increased from slightly more than half at the beginning of the 1990s to almost three- fourths a decade later. While that is an improvement, the World Health Organization and UNICEF recommend a minimum of four antenatal care visits (United Nations 2008). It is well established that taking antenatal care under the supervision of health care providers and giving birth in medical institutions promotes child survival and reduces the risk of maternal mortality. In India, both child mortality (especially neonatal mortality) and maternal mortality are high. Seven out of every 100 children born in India die before reaching age one, and approximately five out of every 1000 mothers who become pregnant die of causes related to pregnancy and childbirth (Population Reference Bureau (PRB) 2007). Despite the many benefits associated with institutional delivery, India's maternal and child health programs have not aggressively promoted institutional deliveries, except in high-risk cases. The reason is that providing facilities for institutional delivery on a mass scale in rural areas is viewed as a longterm goal requiring massive health infrastructure investments. In recent years, however, there has been a shift in this policy with the establishment of the Child Survival and Safe Motherhood and the Reproductive and Child Health programs. The new programs aim at expanding existing rural health services to include facilities for institutional delivery. Existing maternal and child health services at primary health centre are being upgraded, and new first-referral units are being set up at the sub-district level to provide comprehensive emergency obstetric and newborn care (Ministry of Health and Family Welfare 1997-98).

Despite the uniformity in program design throughout the country, there is considerable regional diversity in the availability and quality of health services, including maternal health services. Utilization of health services is affected by a multitude of factors including availability, distance, cost, and quality of services, but also by socio-economic factors and personal health beliefs (National Family and Health Survey (NFHS)-I 1992-93). Another factor affecting women's health-seeking behavior, especially as related to pregnancy and child birth, is that traditionally in rural India pregnancy is considered a natural state of being for a woman 
rather than a condition requiring medical attention and care. Some other factors like women's autonomy and women empowerment are also most important in health behavior. According to Kishor and Gupta (2004), Arokiasamy (2004) noticed that the level of women's autonomy in India varies not only in the states that are doing very poorly or appear so in a large majority of indicators but also in the states that are doing relatively well on women empowerment. Some studies related to women empowerment and demographic factors (Drovandi and Salvini 2004) have been done.

Such perceptions and beliefs constitute a "lay-health culture" that is an intervening factor between the presence of a morbidity condition and its corresponding treatment. Post-natal care and infant and child health care are similarly affected by this culture, with the result that women often do not avail themselves of preventive and curative medical services intended to safeguard their own and their children's health and well-being. The lay-health culture presumably has substantial effects on utilization of maternal health services in regions of the country where poverty and illiteracy are widespread. This culture is difficult to measure directly, but it is possible to include socio-economic factors that are correlated with it when analyzing utilization of maternal health services (Kanitkar and Sinha 1989; Govindasamy 1994; Ahmed and Moseley 1997; Asari and Sathiya Susuman 1998; Sugathan et al.2001). Several studies have attempted to identify and measure the effects of the factors that contribute to differential use of maternal health services. Many of the studies have shown that utilization of maternal and child health services are strongly affected by woman's education (Sathiya Susuman and Asari 2001). Other socio-economic factors usually important are urban rural residence, caste/ tribe membership and household standard of living. Many studies in the past have tries to measure the differences in health care behavior of the general women (Sugathan et al. 2001; Griffiths et al. 2002; Pande 2003; Mishra 2004). But none of those studies tried to study antenatal and post-natal care among tribal married women.

In the present article an attempt is made to relate the socio-economic and demographic characteristics of the currently married Schedule Tribes women belonging to 15-44 age groups in eight districts of Chhatisgarh with the factors associated with antenatal and post natal care. There is no such type of study in Chhatisgarh, especially tribal women's research. One of the Chhattisgarh's eminent tribes is the Gonds or the Kotoriya tribe. The etymological connotation of their name comes from the Telegu term "Kond" meaning hills. The Gonds dominate most of Chhattisgarh's tribal population and primarily depend upon agriculture, forestry, cottage industries, hunting and fishing for their subsistence. The talking point of the lifestyle and culture of the Gond tribals is their Ghotul marriage policy, a one of a kind arrangement for conducting the nuptial rituals.

Another tribe, the Abuj Maria live in isolation in the dense and secluded enclaves of the forests of Narayanpur Tehsil in Basir. Chhatisgarh is a newly created state by sepa-rating sixteen districts of undivided Madhya Pradesh. The population of the state rose by 18.06 per cent during the decade 1991-2001. Chhatisgarh absorbed 37.1 per cent of the schedule tribe population of undivided Madhya Pradesh (Census of India 2001). The present study covers scheduled tribe currently married women of the eight districts of Chhatisgarh. For the analysis purpose eight districts namely, Bastar, Bilaspur, Dhamtari, Janjgiar-Champa, Koriya, Raigarh, Raipur and Rajnandgaon of Chhatisgarh are included.

\section{METHODOLOGY}

Data for this study are taken from District Level Household Survey - Reproductive and Child Health (DLHS-RCH 2002) covering 1569 currently married scheduled tribe women of the age group 15-44. DLHS-RCH collected information on various indicators pertaining to $\mathrm{RCH}$ that would assist policymakers and program managers to formulate and implement the goals set for $\mathrm{RCH}$ programs. The International Institute for Population Sciences (IIPS), Mumbai, the Nodal Agency for DLHS-RCH project has made necessary modifications in the two Questionnaires: Households Questionnaire and Women's Questionnaire and added three more Questionnaires that is, Husband's Questionnaire, Village Questionnaire and Health Questionnaire, in consultation with MoHFW and World Bank. The details of questionnaires are as follows:

Household Questionnaire: The household questionnaire lists all usual residents in each 
sample household including visitors who stayed in the household the night before the interview. For each listed household member, the survey collected basic information on age, sex, and marital status, relationship to the head of the household, education and the prevalence /incidence of tuberculosis, blindness and malaria. Information was also collected on the main source of drinking water, type of toilet facility, source of lighting, type of cooking fuel, religion and caste of household head and ownership of other durable goods in the household. In addition, a test was conducted to assess whether the household used cooking salt that has been fortified with iodine. Besides, details of marriages and deaths which happen to usual residents within reference period were collected. Efforts were also made to get information about maternal deaths.

Woman Questionnaire: Women questionnaire is designed to collect information from currently married women age $15-44$ years who are usual residents of the sample household or visitors who stayed in the sample household the night before the interview.

The women questionnaire covered the following sections:

Section i): Background Characteristics: In this section the information collected on age, educational status and birth and death history of biological children including still birth, induced and spontaneous abortions.

Section ii): Antenatal, Natal and Post- natal Care: In this section the questionnaire collect information only from the women who had live birth, still birth, spontaneous or induced abortion during last three years preceding the survey date. The information on whether women received antenatal and postpartum care, who attended the delivery and the nature of complications during pregnancy for recent births were also collected.

Section iii): Immunization and Childcare: This section gives information about feeding practices, the length of breastfeeding, immunization coverage and recent occurrence of diarrhoea, and pneumonia for young children (below age 3 years).

Section iv): Contraception: This section provides information on knowledge and use of specific family planning methods. Questions were included about reasons for non use, inten- tions about future use, desire for additional child, sex preference for next child etc.

Section v): Assessment of Quality of Government Health Services and Client Satisfaction: In this section the questions are targeted to assess the quality of family planning and health services provided by Government health facilities. The information was also collected about the rating of Government health facilities and staff and reasons for not visiting to government health facilities by eligible woman.

Section vi): Awareness about RTI/STI and HIV/AIDS: In this section the information was collected about women's knowledge of RTI/STI awareness, Source of knowledge, aware of mode of transmission, curability, symptoms and treatment seeking behaviour. About HIV/AIDS, awareness, source of knowledge, aware of mode of transmission and prevention etc. were canvassed.

Husband Questionnaire: In DLHS-RCH, round II, husband questionnaire was used to collect information from eligible women's husbands about age, educational status, knowledge and source of knowledge of Reproductive tract infection (RTI)/ Sexually Transmitted Infection (STI) and HIV/AIDS reported symptoms of RTI/ STI and male participation. Apart from these information desires for children, reasons for not using Family Planning (F.P.) methods, future intention to use F.P. methods and knowledge about no scalpel vasectomy (NSV) has also been collected.

Health Questionnaire: In DLHS-RCH, round II, a health questionnaire was included. The information collected were on weight of children age 0-71 months old and the blood sample to assess the haemoglobin levels of children age 0-71 months old, adolescents 10-19 years old and pregnant eligible women. This information is useful for assessing the levels of nutrition prevailing in the population and prevalence of anaemia among women, adolescent girls and children.

Village Questionnaire: A village questionnaire was also added in this round of DLHS. The information collected on the availability and accessibility of various facilities in the village especially on accessibility of educational and health facilities.

The researcher was really interested to see the information on utilization of specific antenatal and postnatal care services for each preg- 
nancy after January 1999. Bivaraite and multivariate analysis were also undertaken to study the relationship of a set of explanatory (independent) variables with antenatal and post-natal care to determine which variables most affect the dependent variables. There are three dependent variables included in the ana-lysis (District Level Household Survey - DLHS 2002) The multivariate statistical method used in the analysis is logistic regression with dependent variables as Scheduled Tribes women (model I), antenatal care (ANC model II), and post-natal care (PNC model III). Independent variables included in the analysis are related to demographic, socio-economic, antenatal and postnatal care.

\section{RESULTS}

Some of the important listing of variables included in the analysis and their definitions is shown in Table 1. Each variable has rational for inclusion in the analysis. Mother's age and child's birth order are included because they are co-related with antenatal and post-natal services. Caste/tribe variable helps to control variation in health seeking practices. Similarly, various socio-economic variables like women's education and standard of living are related to antenatal and post-natal services. Distance to the hospital within specific range affects access to the health services. Table 2 describes the percentage of currently married tribal rural women who gave births in medical institution during the reference period. It is observed that the older mothers are somewhat less likely to give birth in a medical institution ( 25 per cent) as compared to the women belonging to age group 20-34. Out of total births, 95 per cent of the women had given live births. About threefourths of the tribal women were illiterate and 84 per cent of the women had low standard of living. About 57 per cent of the tribal women had received full antenatal care ANC, that is, 3 ANC check-ups and at least one tetanus toxoid injection and 100+ IFA tablets. Seventy per cent of the tribal women had received two or more tetanus toxoid injections. Around 42 per cent of the tribal women received professional assistance at the time of delivery. It is shocking to note that about 88 per cent of the tribal women did not receive delivery care. Also, about 91 per cent of the children of tribal women did not receive newborn care. In case of 53 per cent of the tribal women, delivery was conducted by untrained dais. With regard to the main reasons for not going to health facility for delivering a baby was given as not necessary (59 per cent) followed by family did not allow (about 20 per cent). About 53 per cent of the tribal women reported the distance to the nearest town for health facility as between 5 to $9 \mathrm{~km}$.

Table 1: Definitions of the variables included in the analysis of births during reference periods DLHS-RCH, 2002 Chhatisgarh

\begin{tabular}{|c|c|}
\hline Variable & Definition \\
\hline \multicolumn{2}{|l|}{ Age (in years) } \\
\hline$<20$ & $\begin{array}{l}\text { Mother's age at the time of the } \\
\text { survey is less than } 20 \text { years }\end{array}$ \\
\hline $20-34$ & $\begin{array}{l}\text { Mother's age at the time of the } \\
\text { survey is } 20-34 \text { years }\end{array}$ \\
\hline 35> & $\begin{array}{l}\text { Mother's age at the time of the } \\
\text { survey is } 35 \text { and above }\end{array}$ \\
\hline \multicolumn{2}{|l|}{ Parity } \\
\hline 1 & First birth \\
\hline 2 & Second birth \\
\hline 3 & Third birth \\
\hline $4+$ & Fourth or higher-order birth \\
\hline \multicolumn{2}{|r|}{ 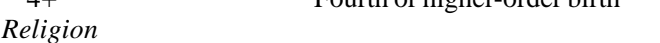 } \\
\hline Hindu & $\begin{array}{l}\text { Mother live in a household } \\
\text { whose head is Hindu }\end{array}$ \\
\hline Other religion & $\begin{array}{l}\text { Mother live in a household } \\
\text { whose head is other religion }\end{array}$ \\
\hline \multicolumn{2}{|l|}{ Caste/Tribe } \\
\hline Scheduled tribe & $\begin{array}{l}\text { Mother live in a household } \\
\text { whose head belongs to a } \\
\text { scheduled tribe }\end{array}$ \\
\hline Other & $\begin{array}{l}\text { Mother live in a household } \\
\text { whose head does not belongs } \\
\text { to a ST }\end{array}$ \\
\hline \multicolumn{2}{|l|}{ Women's Education } \\
\hline Illiterate & Mother is illiterate \\
\hline $\begin{array}{l}\text { Literate, <high school } \\
\text { complete }\end{array}$ & $\begin{array}{l}\text { Mother is literate with less } \\
\text { than high school complete }\end{array}$ \\
\hline High school and above & $\begin{array}{l}\text { Mother is literate with high } \\
\text { school and above education }\end{array}$ \\
\hline \multicolumn{2}{|l|}{ Standard of Living } \\
\hline Low & $\begin{array}{l}\text { Mother lives in a household } \\
\text { with a low standard of living }\end{array}$ \\
\hline Medium & $\begin{array}{l}\text { Mother lives in a household } \\
\text { with a medium standard of } \\
\text { living }\end{array}$ \\
\hline High & $\begin{array}{l}\text { Mother lives in a household } \\
\text { with a high standard of living }\end{array}$ \\
\hline \multicolumn{2}{|c|}{ Received full antenatal Check-up } \\
\hline Yes & $\begin{array}{l}\text { Mother received } 3 \text { ANC check- } \\
\text { ups and at least one TT injec- } \\
\text { tion and } 100+\text { tablets }\end{array}$ \\
\hline No & $\begin{array}{l}\text { Mother did not receive any ante- } \\
\text { natal check-up while preg- } \\
\text { nant with the specified child }\end{array}$ \\
\hline
\end{tabular}


Table 1: Contd.....

\begin{tabular}{|c|c|}
\hline Variable & Definition \\
\hline \multicolumn{2}{|c|}{ Received Two or More Tetanus Toxoid Injections } \\
\hline Yes & $\begin{array}{l}\text { Mother received two or more } \\
\text { tetanus toxoid injections } \\
\text { while pregnant with the } \\
\text { specified child }\end{array}$ \\
\hline Received Professional & $\begin{array}{l}\text { Mother received less than two } \\
\text { tetanus toxoid injections } \\
\text { while pregnant with the } \\
\text { specified child }\end{array}$ \\
\hline \multicolumn{2}{|c|}{ Received Professional Assistance at Delivery } \\
\hline Yes & $\begin{array}{l}\text { Mother received assistance of } \\
\text { a doctor, ANM/LHV, or } \\
\text { nurse/midwife for delivery of } \\
\text { the specified child }\end{array}$ \\
\hline No & $\begin{array}{l}\text { Mother did not receive assis- } \\
\text { tance of a doctor, ANM/LHV, } \\
\text { or nurse/midwife for delivery } \\
\text { of the specified child }\end{array}$ \\
\hline \multicolumn{2}{|c|}{ Delivered in a Medical Institution } \\
\hline Yes & $\begin{array}{l}\text { Mother delivered the specified } \\
\text { child in a medical institution }\end{array}$ \\
\hline No & $\begin{array}{l}\text { Mother did not deliver the spe- } \\
\text { cified child in a medical insti- } \\
\text { tution }\end{array}$ \\
\hline \multicolumn{2}{|l|}{ Delivery Care } \\
\hline Yes & Mother taken delivery care \\
\hline No & $\begin{array}{l}\text { Mother did not taken delivery } \\
\text { care }\end{array}$ \\
\hline \multicolumn{2}{|l|}{ Newborn Care } \\
\hline Yes & Mother taken newborn care \\
\hline No & $\begin{array}{l}\text { Mother did not taken newborn } \\
\text { care }\end{array}$ \\
\hline \multicolumn{2}{|l|}{ Delivery Conducted by } \\
\hline Doctor & Delivery conducted by doctor \\
\hline ANM/Nurse/LHV ${ }^{a}$ & $\begin{array}{l}\text { Delivery conducted by ANM/ } \\
\text { Nurse/LHV }\end{array}$ \\
\hline Trained dai & Delivery conducted trained $d a i$ \\
\hline Untrained dai & $\begin{array}{l}\text { Delivery conducted untrained } \\
\text { dai }\end{array}$ \\
\hline Relatives/friends & $\begin{array}{l}\text { Delivery conducted relatives/ } \\
\text { friends }\end{array}$ \\
\hline None & Delivery conducted none \\
\hline Main Reason For Not & ing to Health Facility for \\
\hline Delivery & \\
\hline Not necessary & $\begin{array}{l}\text { Not going to health facility for } \\
\text { delivery it is not necessary }\end{array}$ \\
\hline Not customary & $\begin{array}{l}\text { Not going to health facility for } \\
\text { delivery it is not customary }\end{array}$ \\
\hline Cost too much & $\begin{array}{l}\text { Not going to health facility for } \\
\text { delivery it is cost too much }\end{array}$ \\
\hline Too far/no transport & $\begin{array}{l}\text { Not going to health facility for } \\
\text { delivery is too far/no transport }\end{array}$ \\
\hline Poor quality service & $\begin{array}{l}\text { Not going to health facility for } \\
\text { delivery it is Poor quality ser- } \\
\text { vice }\end{array}$ \\
\hline No time to go & $\begin{array}{l}\text { Not going to health facility for } \\
\text { delivery it is no time to go }\end{array}$ \\
\hline Family did not allow & $\begin{array}{l}\text { Not going to health facility for } \\
\text { delivery it is family did not } \\
\text { allow }\end{array}$ \\
\hline Better care at home & $\begin{array}{l}\text { Not going to health facility for } \\
\text { delivery is better care at home }\end{array}$ \\
\hline
\end{tabular}

Table 1: Contd.....

\begin{tabular}{|c|c|}
\hline Variable & Definition \\
\hline Lack of knowledge & $\begin{array}{l}\text { Not going to health facility for } \\
\text { delivery is lack of knowledge }\end{array}$ \\
\hline Other reason & $\begin{array}{l}\text { Not going to health facility for } \\
\text { delivery it is some other rea- } \\
\text { sons }\end{array}$ \\
\hline \multicolumn{2}{|c|}{ Availability of a hospital Within $5 \mathrm{~km}$} \\
\hline$<5 \mathrm{~km}$ & $\begin{array}{l}\text { Mother lives in a village that } \\
\text { has a government hospital, a } \\
\text { community health centre/rural } \\
\text { hospital, or a private hospital } \\
\text { within a distance of } 5 \mathrm{~km}\end{array}$ \\
\hline $5-9 \mathrm{~km}$ & $\begin{array}{l}\text { Mother lives in a village that } \\
\text { does not have any government } \\
\text { hospital, community health } \\
\text { centre/rural hospital, or a pri- } \\
\text { vate hospital within a distance } \\
\text { of } 5-9 \mathrm{~km}\end{array}$ \\
\hline
\end{tabular}

${ }^{a}$ ANM denotes auxiliary nurse midwife. LHV denotes lady health visitor

Table 2: Percentage of rural tribal currently married women giving birth in a medical institution during the reference period DLHS-RCH 2002

\begin{tabular}{|c|c|c|}
\hline Variable & of women & Per cent \\
\hline \multicolumn{3}{|l|}{ Age (in years) } \\
\hline$<20$ & 109 & 7.0 \\
\hline $20-34$ & 1064 & 68.0 \\
\hline $35>$ & 391 & 25.0 \\
\hline \multicolumn{3}{|l|}{ Parity } \\
\hline One birth & 320 & 20.4 \\
\hline Two births & 374 & 23.8 \\
\hline Three births & 579 & 36.9 \\
\hline Four and above & 296 & 18.9 \\
\hline \multicolumn{3}{|l|}{ Religion } \\
\hline Hindu & 1555 & 99.1 \\
\hline Other religion & 14 & 0.9 \\
\hline \multicolumn{3}{|l|}{ Caste } \\
\hline Scheduled tribe & 1569 & 25.0 \\
\hline Non-tribe & 4709 & 75.0 \\
\hline \multicolumn{3}{|l|}{ Women's Education } \\
\hline Illiterate & 1168 & 74.4 \\
\hline $\begin{array}{l}\text { Literate < High school } \\
\text { complete }\end{array}$ & 349 & 22.2 \\
\hline High school and above & 52 & 3.3 \\
\hline \multicolumn{3}{|l|}{ Standard of Living } \\
\hline Low & 1318 & 84 \\
\hline Medium & 196 & 13 \\
\hline High & 55 & 3 \\
\hline \multicolumn{3}{|c|}{ Received Full Antenatal Check-up } \\
\hline Yes & 424 & 56.7 \\
\hline No & 324 & 43.3 \\
\hline \multicolumn{3}{|c|}{ Received any Antenatal Check-up } \\
\hline Yes & 521 & 47.4 \\
\hline No & 223 & 52.6 \\
\hline \multicolumn{3}{|c|}{ Received Two or More Tetanus Toxoid Injections } \\
\hline Yes & 522 & 70.0 \\
\hline No & 224 & 30.0 \\
\hline \multicolumn{3}{|c|}{ Received Professional Assistance at Delivery } \\
\hline Yes & 666 & 42.4 \\
\hline No & 903 & 57.6 \\
\hline
\end{tabular}


Table 2: Contd.....

\begin{tabular}{|c|c|c|}
\hline Variable & No. of women & Percent \\
\hline \multicolumn{3}{|c|}{ Delivered in a Medical Institution } \\
\hline Yes & 746 & 47.5 \\
\hline No & 823 & 52.5 \\
\hline \multicolumn{3}{|l|}{ Delivery Care } \\
\hline Yes & 90 & 12.0 \\
\hline No & 656 & 87.9 \\
\hline \multicolumn{3}{|l|}{ Newborn Care } \\
\hline Yes & 68 & 9.1 \\
\hline No & 678 & 90.9 \\
\hline \multicolumn{3}{|l|}{ Delivery Conducted by } \\
\hline Doctor & 22 & 3.3 \\
\hline ANM/Nurse/LHVa & 30 & 4.5 \\
\hline Trained dai & 102 & 15.3 \\
\hline Untrained dai & 354 & 53.2 \\
\hline Relatives/friends & 154 & 23.2 \\
\hline None & 3 & 0.5 \\
\hline \multicolumn{3}{|c|}{ Main Reason Did Not Go to Health Facility For Delivery } \\
\hline Not necessary & 394 & 59.2 \\
\hline Not customary & 18 & 2.7 \\
\hline Cost too much & 27 & 4.1 \\
\hline Too far/no transport & 6 & 0.9 \\
\hline Poor quality service & 22 & 3.3 \\
\hline No time to go & 8 & 1.2 \\
\hline Family did not allow & 130 & 19.5 \\
\hline Better care at home & 38 & 5.7 \\
\hline Lack of knowledge & 10 & 1.5 \\
\hline Other reason & 1 & 0.2 \\
\hline \multicolumn{3}{|c|}{ Availability of a Hospital Within $5 \mathrm{~km}$} \\
\hline$<5$ & 41 & 46.6 \\
\hline $5-9$ & 47 & 53.4 \\
\hline
\end{tabular}

Table 3 presents adjusted effects (odds ratios) of selected background, demographic, socio-economic, antenatal and post-natal care variables on the likelihood of giving birth in a medical institution. The analysis is limited to rural areas of eight districts of Chhatisgarh state because information on community access to health facilities was collected only for rural tribal women in DLHS-RCH, 2002. Effects are "adjusted" by statistically controlling for potentially confounding variables by holding them constant at their mean values in the underlying logistic regression. For eight districts of the Chhatisgarh state, three alternative models are estimated using alternative sets of predictor variables. Adjusted effects of scheduled tribe currently married women; antenatal care and post-natal care on maternal delivery care are included in the analysis.

\section{DISCUSSION}

The bivariate relationships presented in the previous section reveal a strong positive
Table 3: Adjusted effects (odds ratios) of selected predictor variables on the likelihood of giving birth in a medical institution in tribal women of Chhatisgarh: DLHS-RCH, 2002

\begin{tabular}{|c|c|c|c|}
\hline $\begin{array}{l}\text { Characteristics } \\
\text { dependent va- } \\
\text { riables }\end{array}$ & $\begin{array}{l}\text { Model I } \\
\text { (Scheduled } \\
\text { Tribe) }\end{array}$ & $\begin{array}{l}\text { Model II } \\
\text { Full ANC }\end{array}$ & $\begin{array}{l}\text { Model III } \\
\text { PNC }\end{array}$ \\
\hline \multicolumn{4}{|l|}{ Demographic } \\
\hline \multicolumn{4}{|l|}{ Age (in years) } \\
\hline$<20^{@}$ & 1.00 & 1.00 & 1.00 \\
\hline $20-34$ & $2.07 *$ & $2.22 *$ & $1.88^{*}$ \\
\hline $35>$ & $2.02 *$ & $2.37 * *$ & 1.76 \\
\hline \multicolumn{4}{|l|}{ Parity } \\
\hline $1^{@}$ & 1.00 & 1.00 & 1.00 \\
\hline 2 & $0.35 *$ & 0.46 & $0.33 *$ \\
\hline $3+$ & $0.38 * *$ & $0.31 *$ & $0.27 *$ \\
\hline \multicolumn{4}{|c|}{ Demand Factors-Socio-Economic Women's Education } \\
\hline Illiterate $^{@}$ & 1.00 & 1.00 & 1.00 \\
\hline $\begin{array}{l}\text { Literate, }<\text { middle } \\
\text { complete }\end{array}$ & $2.81 *$ & $2.12 *$ & $2.55^{*}$ \\
\hline $\begin{array}{l}\text { Middle complete or } \\
\text { higher }\end{array}$ & $3.95 * *$ & $3.50 *$ & $3.33 * *$ \\
\hline \multicolumn{4}{|l|}{ Standard of Living } \\
\hline Low ${ }^{@}$ & 1.00 & 1.00 & 1.00 \\
\hline Medium & $0.89 *$ & $0.75^{*}$ & $1.02 *$ \\
\hline High & $1.23 *$ & $1.10^{*}$ & $0.97 *$ \\
\hline \multirow{2}{*}{\multicolumn{4}{|c|}{$\begin{array}{l}\text { Demand Factors-Antenatal Care Received Full Antenatal } \\
\text { Check-up }\end{array}$}} \\
\hline & & & \\
\hline Yes & $2.54 *$ & & $1.85^{*}$ \\
\hline $\mathrm{No}^{@}$ & 1.00 & & 1.00 \\
\hline \multicolumn{4}{|c|}{ Received Two or More Tetanus Toxoid Injections } \\
\hline Yes & $1.42 *$ & 0.94 & $0.92 *$ \\
\hline $\mathrm{No}^{@}$ & 1.00 & 1.00 & 1.00 \\
\hline \multicolumn{4}{|c|}{ Supply Factors Availability of Hospital Within $5 \mathrm{~km}$} \\
\hline Yes & $1.66^{*}$ & 0.92 & 0.73 \\
\hline $\mathrm{No}^{@}$ & 1.00 & 1.00 & 1.00 \\
\hline \multicolumn{4}{|c|}{ Demand Factors-Postnatal Care Delivery Care } \\
\hline Yes & $0.22 *$ & & \\
\hline $\mathrm{No}^{@}$ & 1.00 & & \\
\hline \multicolumn{4}{|l|}{ Newborn Care } \\
\hline Yes & 1.14 & $0.87 *$ & $0.55^{*}$ \\
\hline $\mathrm{No}^{@}$ & 1.00 & 1.00 & 1.00 \\
\hline \multicolumn{4}{|c|}{ Received Treatment for Post Delivery Complication } \\
\hline Trained & $0.96^{*}$ & $0.85^{*}$ & $0.88^{*}$ \\
\hline Untrained $^{@}$ & 1.00 & 1.00 & 1.00 \\
\hline
\end{tabular}

${ }^{@}$ Reference category, $* \mathrm{p}<.05 * * \mathrm{p}<.01$

Note: Adjusted effects (odds ratio) for religion have not been estimated as 99 per cent of the population is of Hindus.

bFull ANC: 3ANC check-ups and at least one tetanus toxoid injection and 100+ IFA tablets

correlation between antenatal and postnatal care. Table 3 presents adjusted effects of scheduled tribe women, antenatal care and postnatal care on the likelihood of maternal care for Chhatisgarh tribal currently married women based on three alternative models. The above three variables are included in Models 1, 2 and 3. Three logistic regression models have been used to estimate the influence of socio-economic and demographic factors on scheduled tribe 
women, antenatal care and post-natal care, which are treated as dependent variables. These variables are provided as dichotomous variables. The results of logistic regression analysis on the maternal care variables regressed on socioeconomic and demographic variables are given in Table 3. The independent variables except age (in year), birth order and education (continuous) are treated as dummy variables. The dependent variables are scheduled tribes and others with values, ST women $=1$ and other women $=0$. Other dependent variables are antenatal and post-natal care with values, Yes $=1$ and $\mathrm{No}=0$, for having received or not having received the above maternal care. The independent variables used were, standard of living, received two or more tetanus toxoid injections, availability of hospital within $5 \mathrm{~km}$, delivery care, new born care, delivered in medical institution and received treatment for post delivery complication. All these factors have been used as explanatory variables in the equation to know the relative influence of each factor on the maternal care in the three models.

Table 3 shows that in Chhatisgarh DLHS$\mathrm{RCH}$, in Model I with age, birth order, women's education and standard of living controlled by holding them constant at their mean values in the underlying logistic regression the odds of giving births in the medical institution for scheduled tribe women who received full antenatal check up is 2.5 times higher than women who did not receive any antenatal check-up. Having received two or more tetanus toxoid injections during pregnancy also has a positive effect on the institutional delivery, but this effect is much smaller (1.4 times more than those who did not receive any tetanus toxoid injection) as compared to those women who received full antenatal care. Mother's age has long positive effect on the odds of institutional delivery when other variables including birth order are controlled. Childs' birth order, on the other hand has a strong negative effect when other variables, including mother's age are controlled. The odds of institutional delivery are almost three times has high for first order birth as for second order births. The opposite effects of maternal age and childbirth order indicate that women who delay child bearing are more likely to deliver in medical institution. With all of the other predictor variables controlled, the odds of institutional delivery are three to four times higher for mothers with middle school or higher education than for illiterate mothers.

Those Scheduled Tribe women who have a higher standard of living have 1.2 times higher chance of delivering a baby in a medical institution as compared to those having low standard of living. Availability of hospital within 5 $\mathrm{km}$ also has a positive effect on delivering a baby in a medical institution. Those tribal women who received full antenatal care are also likely to go for post-natal care. The odds of receiving postnatal care are almost two times more for tribal women who went for institutional delivery as compared to those who did not avail postnatal care. Those women with middle or higher level of education were likely to take post-natal care three times more than those who were illiterate.

\section{CONCLUSION}

It is observed that the older mothers are somewhat less likely to give birth in a medical institution ( 25 per cent) as compared to the women belonging to age group 20-34. About 57 per cent of the tribal women had received full ANC, that is, 3 ANC check-ups and at least one tetanus toxoid injection and 100+ IFA tablets. Seventy per cent of the tribal women had received two or more tetanus toxoid injections. The main problem with the bivariate approach is that it ignores the possibility that a collection of variables, each of which could be weakly associated with the outcome can become an important predictor of the outcome when taken together. Hence, multivariate regression approach that takes into account the drawback mentioned by the bivariate technique is considered in the analysis.

Model I with age, birth order, women's education and standard of living controlled by holding them constant at their mean values in the underlying logistic regression the odds of giving births in the medical institution for scheduled tribe women who received full antenatal check up. The opposite effects of maternal age and childbirth order indicate that women who delay child bearing are more likely to deliver in medical institution. With all of the other predictor variables controlled, the odds of institutional delivery are three to four times higher for mothers with middle school or higher education than for illiterate mothers. 
Availability of hospital within $5 \mathrm{~km}$ also has a positive effect on delivering a baby in a medical institution. Those tribal women who received full antenatal care are also likely to go for post-natal care. Those women with middle or higher level of education were likely to take post-natal care three times more than those who were illiterate. In order that have more tribal women should avail the facility of antenatal care and delivery care services and also post-natal care it is necessary to spread the awareness and education among tribal women. Also, it is necessary to increase the economic standard of the tribal women. Other important finding suggests that the availability of health facilities should be brought within the distance of $5 \mathrm{~km}$ from tribal women's place of residence. Women's pregnancy contributes to the cycle of maternal deaths and childhood mortality. Very early motherhood not only increases the risk of dying in childbirth, it also jeopardizes the well-being of surviving mothers and their children.

Overall, most poor tribal women are caught in a vicious circle. Breaking this circle requires an array of simultaneously actions: single intervention is unlikely to be sufficient. Government should ensure that antenatal and postnatal care is mainstreamed into all policies, ranging from national strategy to local level administrative actions. Particular attention should be paid to the creation of additional opportunities for decent work. Public investment and public institutions should endeavour to target the poor tribal, particularly in their expenditures on education, health and infrastructure.

\section{REFERENCES}

Ahmed Saifuddin, Moseley W Henry 1997. Simultaneity in Maternal-child Health Care Utilization and Contraceptive Use: Evidence from Developing Countries. New Delhi. Baltimore, Maryland: Department of Population Dynamics, School of Public Health, John Hopkins University.

Arokiasamy P 2004. Regional patterns of sex bias and excess female child mortality in India. Population-E, 59(6): 833-864.
Asari V Gopalakrishnan, Sathiya Susuman A 1998. Reproductive health of women in declining fertility: A study of married women in Kerala. Journal of Health and Population Perspectives and Issues, 21(2): 91103.

Census of India 2001. Provisional Population Totals: India, Paper 1 of 2001, Chhatisgarh. New Delhi: Office of the Registrar General and Census Commissioner, India.

Drovandi S, Salvini S 2004. Women's autonomy and demographic behavior in India. Population and Development Review, 9(1): 35-60.

Govindasamy P 1994. Poverty, Women's Education and Utilization of Health Services in Egypt. Paper presented at International Union for the Scientific Study of Population (IUSSP), Liege, Belgium.

Griffiths P, Mathews Z, Hinde A 2002. Gender, family and the nutritional status of children in three culturally contrasting states of India. Social Science and Medicine, 55(5): 775-790.

Jejeebhoy SJ, Sathar AZ 2001. Woman's autonomy in India and Pakisthan: The influence of religion and region. Population and Development Review, 27(4): 687-711.

Kanitkar T, Sinha RK 1989. Antenatal care services in five States of India. In: S N Singh, MK Premi, P S Bhatia, Ashish Bose (Eds.): Population Transition in India. Vol. 2. Delhi: B.R. Publishing, pp. 201-211.

Kishor S, Gupta K 2004. Women's empowerment in India and its states: Evidence from NFHS. Economic and Political Weekly, 39(7): 694-714.

Ministry of Health and Family Welfare 1998. Аnnual Report, 1997-98. New Delhi: Ministry of Health and Family Welfare.

Mishra V, Roy TK, Retherford R 2004. Sex differentials in childhood feeding, health care and nutritional status in India. Population and Development Review, 30(2): 269-295.

National Health and Family Survey 1995. Maternal and Child Health and Family Planning in India. Mumbai: International Institute for Population Sciences India.

Pande R 2003. Selective gender differences in childhood nutrition and immunization in rural India: The role of siblings. Demography, 40(3): 395-418.

Population Reference Bureau 2007. Population Data Sheet. Washington DC: Population Reference Bureau.

Sathiya Susuman A, Asari V Gopalakrishnan 2001. Reproductive health care of women in rural areas: An exploratory study in Nilgiris District in Tamil Nadu. The Journal of Family Welfare, 47(1): 50-55.

Sugathan KS, Mishra Vinod, Robert D Retherford 2001. Promoting Institutional Deliveries in Rural India: The Role of Antenatal-Care Services. National Family Health Survey Subject Reports, No. 20, December 2001, New Delhi-NFHS.

United Nations 2008. The Millennium Development Goals Report. New York: United Nations. 